\title{
Transitando identidades. La mediación artística en el proceso de rehabilitación de personas con problemas de adicciones
}

\section{Passing through Identities: Artistic Mediation in the Rehabilitation Process of People with Addiction Problems}

\author{
Ascensión Moreno GonZÁLEZ \\ Universitat de Barcelona \\ amorenog@ub.edu \\ Sonia UsÁN \\ Centro de Atención y Seguimiento \\ a las Drogodependencias de Sants \\ soniausan@hotmail.com \\ Carlos CRIADO \\ c.criado.perez@hotmail.com \\ Alejandro SANTAFORENTINA
jsantaflorentina@gmail.com
}

Recibido: $16 / 11 / 2012$

Revisado: 22/12/2012

Aceptado: 26/04/2013

Disponible on line: 20/12/2013

\section{Resumen}

Durante los años 2010 y 2011, dos voluntarios, estudiantes de la Facultad de Bellas Artes de la Universidad de Barcelona, han desarrollado un proyecto en el Centre d'Atenció i Seguiment a personas con problemas de adicciones (CAS) del barrio barcelonés de Sants. Presentamos el marco teórico y las experiencias con el objetivo de corroborar cómo la experiencia artística contribuye al proceso de reinserción social de estos sujetos.

Palabras clave: mediación artística, voluntariado, identidad, problemas de adicción, reinserción social.

\section{Abstract}

During 2010 y 2011, two volunteers, students from the Faculty of Fine Arts from the University of Barcelona, have developed a project in a support center for people with addiction problems. This center is Centre d'Atenció i Seguiment (CAS) in Sants district from Barcelona. In this article we present the theoretical framework and the experiences in order to substantiate how artistic experience contributes to the process of social reintegration of these individuals.

Keywords: artistic mediation, volunteering, identity, drug-related problems, social reintegration.

Referencia normalizada: Moreno González, A., Usán, S., Criado, C., y Santaforentina, A. (2013): «Transitando identidades. La mediación artística en el proceso de rehabilitación de personas con problemas de adicciones» Cuadernos de Trabajo Social, 26(2): 445-454.

Sumario: Introducción. 1. Escribiendo de forma colaborativa. 2. El Centro de Atención y Seguimiento a las Drogodependencias de Sants. 3. La problemática de las adicciones y los usuarios del taller. 4. La mediación artística como marco de referencia. 5. Los talleres. 6. La voz de los participantes. 7. Conclusiones. 8. Referencias bibliográficas. 


\section{Introducción}

Este artículo está escrito a cuatro manos: las de los educadores artísticos que han desarrollado el proyecto de mediación artística en el Centre d'Atenció i Seguiment a personas con problemas de adicciones de Sants, la educadora social del centro, y la docente cuya asignatura «Intervención Educativa en Contexto Social», de la Facultad de Bellas Artes de la Universidad de Barcelona, ha sido el marco teórico de referencia.

Estructuramos el redactado en siete apartados. En el primero planteamos el sentido de realizar el artículo de forma colaborativa. A continuación contextualizamos el Centre d'Atenció i Seguiment a personas con problemas de adicciones de Sants y nos detenemos brevemente en la problemática de las adicciones. Posteriormente, describimos el proyecto que hemos llevado a cabo y lo enmarcamos en la perspectiva de la Mediación Artística (la actividad artística como herramienta para la inserción social, para finalizar recogemos la valoración de los participantes en los talleres, y las conclusiones a las que llegamos después de transitar por este proyecto, primero de intervención y actualmente de redacción de este artículo, al que titulamos «transitando identidades» por dos motivos. El primero porque el gerundio nos sugiere algo inacabado, en proceso, idea que relacionamos con el transcurso del quehacer artístico. El segundo porque partimos de una idea de identidad no fija y única, sino cambiante y poliédrica, que nos permite posicionarnos ante los sujetos con los que trabajamos desde una mirada diversa y no estigmatizadora, viendo a la persona en su conjunto, y fijándonos especialmente en sus capacidades, que son múltiples. De la misma manera entendemos que nosotros, quienes estamos en estos momentos escribiendo este artículo, también transitamos por distintos roles, que no son estancos y que nos permiten «estar» en diferentes contextos y desde diferentes posiciones, que rompen con el estereotipo del "profesor», el «alumno»y el «profesional».

\section{Escribiendo de forma colaborativa}

A las funciones históricas tradicionales de la universidad de conjugar la enseñanza con la investigación, se ha ido sumando el discurso sobre la necesidad de insertarla en su entorno so- cial y para ello el fomento de la cooperación entre los diferentes agentes implicados resulta clave (Berger, 1999; Aparicio Acosta, 2000). Jiménez Vivas (2009) plantea:

La calidad de una universidad, o de un sistema universitario en general, no puede considerarse, desde un enfoque global, sin contemplar la adecuación del producto que sale de sus aulas a las demandas sociales y productivas del mercado de trabajo donde se insertan dichos productos.

En este sentido consideramos que los centros de la red social necesitan actividades mediadoras de su trabajo socioeducativo y que la mediación artística es una propuesta clave para mejorar sus prácticas educativas.

En el año 2004 iniciamos en la Facultad de Bellas Artes de la Universidad de Barcelona una asignatura que denominamos Intervención Educativa en Contexto Social, y que a partir de la actual reforma universitaria ha pasado a denominarse en los estudios de grado «Arte e Intervención Social». En ella pretendemos acercarnos a las problemáticas sociales contemporáneas, ver cómo la red social las atiende con el objetivo de mejorar la autonomía de las personas afectadas por esas dificultades, así como mejorar las condiciones generales que favorecen situaciones de vulnerabilidad y promover la reinserción social de aquellos que en algún momento habían quedado excluidos, $\mathrm{y}$, por último, conocer cómo las actividades artísticas son una herramienta para la inserción social, que es lo que conocemos como Mediación Artística.

En este marco los alumnos han venido desarrollando proyectos de investigación en diferentes centros de la red social. Actualmente nos planteamos dar un paso más allá de la docencia y de la promoción de la investigación en este campo, generando procesos de colaboración entre los centros, los estudiantes y los docentes. Y en este sentido, y como parte de la orientación del Grupo de Innovación docente Indaga-t, del que la docente forma parte, nos proponemos generar textos y materiales que recojan los procesos de investigación, intervención educativa y cooperación con los centros sociales, que venimos desarrollando.

Con la experiencia de redacción de este artículo queremos abandonar los roles tradiciona- 
les de los implicados en procesos de enseñanza/ aprendizaje e intervención socioeducativa/usuarios de los servicios de la red social. Pretendemos salir del papel del docente como transmisor de conocimiento, del alumno como receptor de las enseñanzas del profesor o profesora, del profesional o la profesional como aquel o aquella que realiza las intervenciones en los servicios y de los usuarios y usuarias como beneficiarios del oficio del experto o la experta.

Nos planteamos redactar este artículo de forma colaborativa entre la docente de la asignatura, que ha promovido el desarrollo del proyecto de intervención; los estudiantes, que yendo más allá de la propuesta recibida, se aventuraron a desarrollar no solo un trabajo de investigación en el Centre d'Atenció i Seguiment a personas con problemas de adicciones de Sants, sino que han estado realizando proyectos de mediación artística durante dos años consecutivos; y la Educadora Social del centro, que ha apoyado el desarrollo de estos talleres artísticos. Nos resultaría sumamente complicado plantearnos la colaboración en esta redaccióno de los usuarios participantes en los talleres, pero sí que recogemos su opinión sobre la participación en los mismos, a partir de generar un grupo de discusión con ellas y ellos, que son parte fundamental de este engranaje que ha estado funcionando durante dos años.

\section{El Centro de Atención y Seguimiento a las Drogodependencias de Sants}

El CAS ${ }^{1}$ está situado en el barrio barcelonés de Sants. El objetivo general es la eliminación o reducción de los efectos nocivos derivados del uso de sustancias (alcohol, cocaína, heroína, cannabis, drogas de síntesis, etc.) en las diferentes áreas que afectan al individuo (enfoque biopsicosocial). Ofrece servicio ambulatorio de atención psiquiátrica, psicológica y socioeducativa a personas en proceso de deshabituación, así como de reducción de daños con dispensario de metadona. A lo anterior, se suman las funciones propias de un equipamiento de acogida diurna, Centro de Día, donde se desarrollan actividades de inserción social complementarias a los procesos de tratamiento terapéutico.
El Centro de Día está dirigido a aquellos pacientes que están en tratamiento en el Centre d'Atenció i Seguiment a personas con problemas de adicciones. Los profesionales del centro, psiquiatra, médico, enfermería, psicólogo, trabajadora social, o educadora, son los que derivan a este espacio. El paciente se incluye en este servicio tras una evaluación previa por el equipo terapéutico $y$, una vez finalizada, firma un contrato, donde se compromete a cumplir una serie de normas, tales como: control y pauta médica, mantener la abstinencia, cumplir un horario, respetar el funcionamiento global del servicio y sus instalaciones, así como mantener el respeto por los compañeros. Este servicio es el marco en el que se inscribe el proyecto al que nos referimos. El principal objetivo general del Centro de Día es ofrecer a sus usuarios un espacio de contención, control, recuperación y aprendizaje en la adquisición de habilidades sociales, con el fin de disminuir los riesgos biopsicosociales derivados del consumo, mejorar el tratamiento de sus usuarios y potenciar la participación comunitaria.

El Centro de Día incide en sus objetivos a través de diversas herramientas terapéuticas. Entre ellas distinguimos: actividades deportivas, actividades intelectuales, cuidado del cuerpo, habilidades de la vida diaria, y actividades artísticas. Se realizan de lunes a viernes de $9 \mathrm{~h}$ a $14 \mathrm{~h}$, son coordinadas por la educadora social del centro y llevadas a cabo con la participación de voluntarios especializados. La experiencia y la colaboración de estos voluntarios dan un valor añadido al servicio y ayudan a romper la imagen estereotipada del drogodependiente, ayudándole a rescatar y a desarrollar sus cualidades a través de los talleres, sintiéndose así que forman parte de la comunidad. Actualmente el Centro recibe semanalmente la colaboración de 16 voluntarios con edades comprendidas entre los 21 y los 77 años.

\section{La problemática de las adicciones y los usuarios del taller}

Hoy en día la problemática de las adicciones en nuestro contexto presenta características distintas a las que eran habituales en los años 1980,

${ }^{1}$ CAS (Centro de Atención y seguimiento a las Drogodependencias) es un centro de tratamiento ambulatorio de la Agencia de Salud Pública de Barcelona (ASPB), gestionado por la ONG Asociación Bienestar y Desarrollo (ABD). 
cuando estalló el consumo de heroína. Actualmente atendemos a personas que pertenecen a familias sin riesgo de exclusión social, y no tanto a familias desestructuradas como anteriormente. Algunas personas presentan un trastorno mental asociado: esquizofrenia, depresión, bipolaridad, trastornos anímicos y de ansiedad, etc., que es lo que denominamos patología dual. También se da el caso de pacientes que presentan poca conciencia para identificar/aceptar el problema que sufren, proyectándolo sobre otras personas/circunstancias, así como la dificultad para apreciar el grado en que les afecta a la salud.

Estamos de acuerdo con José Crespo y Cristina O'Ferral (2005), cuando afirman: «La persona reduce progresivamente su campo de intereses y sus obligaciones, de manera que la conducta adictiva termina por acaparar su vida. La adicción por definición implica pérdida de libertad, por lo que tiene carácter pernicioso». De modo que los objetivos que anteriormente se basaban en la contención y en proporcionar al drogodependiente un espacio alternativo a la calle, ahora se plantean desde la necesidad de trabajar desde lo biopsicosocial. También queremos destacar que el trabajo del centro no se restringe a la persona con el problema de adicción, sino que también intervenimos con su entorno familiar y social.

Las personas que participan en el Centro de Día son un grupo dinámico en su número formado por entre unas 10 y 15 personas adultas, sin experiencia previa en talleres artísticos, que acuden diariamente a este espacio por voluntad propia, siendo la fecha de salida consensuada junto con el paciente y los profesionales del centro; que han abandonado el consumo activo, teniendo en cuenta que la recaída puede formar parte del proceso, aunque también se dan casos de personas que están consumiendo $\mathrm{y}$, que tras la valoración de los profesionales, se considera el Centro de Día como un espacio de reducción de daños, de aprendizaje de la gestión del tiempo libre, o incluso el crear de nuevo estructura y orden de vida.

\section{La mediación artística como marco de referencia}

La mediación artística (Moreno, 2010) es el punto de partida para la organización de los talleres. Moreno plantea «Llamo a este modelo
Mediación Artística porque pone el acento en la idea de que el Arte es una herramienta, es decir, en lo que la experiencia artística posibilita, al margen de sus resultados»». Esto no quiere decir que no valoremos el producto final pero no es lo más importante. Lo que nos interesa es lo que la experiencia artística promueve o posibilita, las ventanas que abre, los recorridos personales que propone, en definitiva, los procesos que facilita a los sujetos. El objetivo de la mediación artística no es formar artistas, ni el aprendizaje de técnicas expresivas, ni realizar obras exquisitas. El taller de arte es una herramienta para la reinserción y la transformación social.

Uno de los aspectos fundamentales de la mediación artística es que no trabaja a partir de los problemas, sino que lo hace a partir de la parte sana del sujeto, que es su capacidad de crear. Huimos de esta forma de la estigmatización, de la mirada reduccionista sobre el otro que se fija en lo que no sabe hacer o en qué barreras tendría que superar. No nos centramos en las dificultades. Partimos de las capacidades y trabajamos permitiendo que de desarrollen.

En nuestros talleres hemos trabajado en torno al concepto de identidad. A menudo se entiende la categoría de identidad como algo que nos define en esencia. Esto es distinto a lo que sostenemos. En lugar de esta idea esencialista compartimos la sencilla definición que ofrece Maffesoli (2004): la identidad no es más que la aceptación de ser algo determinado. Nos interesa esta perspectiva, entre otras cosas, porque si la identidad no es más que la aceptación de ser algo determinado, este algo es susceptible de ser modificado según las situaciones. Nosotros partimos de la idea del sujeto con capacidades para crear. Esta es precisamente la base de nuestra propuesta, no asumir una identidad fija nos permite librarnos de presuposiciones que condicionen nuestra manera de actuar, nos permite librarnos de juzgar nuestros actos en base a lo que se debería esperar de nosotros, nos ayuda a subvertir los discursos establecidos y a desapegarnos de aquellas construcciones que nos incomodan. En definitiva, nos permite prestar atención a lo que nos mueve, de lo que somos capaces, y no a lo que se supone que somos o deberíamos ser. En el caso concreto de la drogodependencia, esta perspectiva nos permite deshacernos de ciertas máscaras o desvincularnos de las etique- 
tas que la sociedad despliega alrededor de la figura del drogadicto, y de su propia imagen sujeta al problema de la adicción.

En cuanto a la planificación de los talleres, no es necesario programar cada una de las sesiones, como unidades didácticas. Se trata de plantearles los objetivos del taller y de recoger los intereses del grupo, poniendo a su disposición las técnicas y procedimientos que necesitan para desarrollar sus ideas y el material necesario. Esto no quiere decir que nunca podamos realizar propuestas, podemos hacerlo, pero tienen que estar relacionadas con medios, útiles, procedimientos, técnicas, maneras de trabajar, etc., y no plantear qué queremos que hagan y de qué manera les proponemos que lo realicen. Frecuentemente los grupos que no han tenido experiencias previas en talleres artísticos no saben por dónde empezar a trabajar. En ese caso resulta de gran ayuda empezar por propuestas sencillas, como fue en nuestro caso la creación de personajes, pero también se puede partir del uso de ciertos materiales, o proponer determinados procedimientos.

Es importante que en la estructuración del taller dediquemos un espacio final a la puesta en común del trabajo realizado en cada una de las sesiones. Este es un momento fundamental para lo que la Gestalt plantea como «darse cuenta». «En el taller ocurre algo similar a lo que nos sucede cuando soñamos: aparecen imágenes que contienen un relato. Cuando nos despertamos nos acordamos de fragmentos del sueño, y si dedicamos un tiempo a repensarlo, e incluso a escribirlo, podemos reconstruir buena parte del mismo e intentar encontrar significados. Si no dedicamos ese tiempo al contenido del sueño se evapora en unas horas. Lo mismo ocurre en el taller. En las producciones aparecen significados simbólicos que si no se dedica un tiempo a hablar sobre las obras, se pierde» (Moreno, 2010). La puesta en común también es un espacio donde, además de tomar conciencia de los contenidos que están apareciendo en las obras, se puede hablar de las dinámicas grupales y de la relación entre los participantes. Cuando se plantea la realización de la actividad creativa en grupo, es más que probable que aparezcan conflictos entre las personas. Podemos reflexionar conjuntamente sobre diferentes maneras de hacer, sobre los significados de nuestras intervenciones y las ajenas, sobre cómo nos influye la mirada del otro. La actividad nos permite de esta forma trabajar los problemas relacionales que ocurren en el taller, que seguramente serán un reflejo de los problemas relacionales que los participantes tendrán en general en su vida.

Es fundamental para que el taller de mediación artística funcione que se cree un espacio de seguridad donde los participantes puedan expresarse sin miedo a ser juzgados, ridiculizados o censurados. Cualquier manifestación, por excéntrica o extraña que resulte, ha de ser respetada y acogida, sin excepción. Y el rol del educador será acompañar el proceso de creación aportando, cuando sea necesario, sus conocimientos técnicos para resolver los problemas que se vayan presentando.

\section{Los talleres}

El proyecto que describimos se dividió en dos talleres: el primero tuvo lugar entre enero y junio de 2010 y el segundo entre octubre de 2010 y junio de 2011. Ambos tenían lugar durante un día a la semana, con una duración de una hora y media. Se trabajó con un grupo de personas con edades entre los 20 y los 60 años. Ambos talleres constituyen un proceso continuo, donde la experiencia y resultados del primero, determinaron el planteamiento del segundo.

\subsection{Fundamentación teórica y metodológica}

Como hemos planteado anteriormente la mediación artística descrita por Moreno constituyó el marco de referencia para la programación de los talleres. La principal apuesta metodológica fue crear un espacio que posibilitara la elaboración simbólica a través de la experiencia artística y la actividad lúdica.

En cuanto a la utilización de los lenguajes artísticos, el primero partió del aprendizaje de técnicas plásticas como pintura y dibujo, para finalizar adoptando el video y la fotografía para vehicular la actividad. El segundo taller profundizó en el desarrollo de estas técnicas, complementándolas con el uso de la performance.

El uso del lenguaje audiovisual resultó adecuado para los objetivos del taller. La cámara de vídeo creaba un espacio privilegiado, una puesta en escena, que permitía la transferencia de relatos que no tenían otro lugar en el que expresarse. Las acciones grabadas eran escenifi- 
cadas, teatralizadas. De una forma distinta a lo que ocurriría en un diálogo con otra persona, la cámara de vídeo permitía exteriorizar emociones, conflictos o hechos, sin sentirnos juzgados, ya que estamos haciendo ficción. En este sentido, aquel que participa está repitiendo parte de sus pensamientos y emociones en la escenificación de su personaje, es un acto reiterativo, en tanto que aquello que pienso o siento lo repito fuera de mí. Por otra parte, en el momento en que observamos las imágenes que hemos tomado incidimos en el aspecto reiterativo, que permite asumir lo expresado, entenderlo. Las performances funcionan como actos vitales de transferencia, transmitiendo saber social, memoria, y sentido de identidad a través de acciones reiteradas (Taylor, 2007). En este sentido, podemos definir performance como el acto vital de reiterar un saber a través de su escenificación en un espacio privilegiado, que permite su entendimiento. Es el hecho de reiterar el saber a través de su escenificación lo que permite restaurarlo, completarlo. Esto, de hecho, en tanto que reelabora un saber o una visión del mundo, desencadena un proceso de elaboración simbólica.

Durante el desarrollo de los talleres valoramos las producciones del grupo, pero lo más importante fue su experiencia artística y los procesos que facilitó a los sujetos. La experiencia artística, como campo de elaboración simbólica, permite a la persona proyectarse en el proceso que lleva a cabo y reelaborar sucesos o relatos personales abriendo la posibilidad a generar nuevas proyecciones de uno mismo. Partimos de las capacidades individuales y grupales, permitiendo su desarrollo. Esto se vincula con la toma de conciencia y la visualización del cambio — según plantea Paolo Freire-y actuó a dos niveles, por un lado permitía potenciar el descubrimiento de habilidades desconocidas, u olvidadas. Por otro, y en línea con el concepto de identidad, ayudaba a cuestionar los roles asumidos como propios, dando la posibilidad de desvincularse de ciertas consideraciones negativas sobre la persona.

Así mismo, se optó por la flexibilidad de marco de trabajo y de los contenidos. No programamos unidades didácticas; planteamos los objetivos del taller y recoger los intereses del grupo, poniendo a su disposición las técnicas, los procedimientos y el material que necesita- ron para desarrollarlos. Esta estructura favorecía la incorporación de elementos tomados del contexto social y político del momento y de las aportaciones espontáneas que aparecieron durante el desarrollo. Con el objetivo de construir conocimiento de forma colectiva, en las sesiones se invitaba a los usuarios a hacer aportaciones: ideas, registrar imágenes fuera del tiempo del taller o aportar material existente como fotos propias, trozos de video, etc.

Por último, la adhesión a la actividad era voluntaria y se respetaba la no actividad. En cada una de las sesiones se contemplaba un espacio final de reflexión. En el primer taller se empleó este espacio para el análisis a un nivel técnico y de resolución de conflictos. Sin embargo, el segundo se dirigió a la interpretación del contenido simbólico; era importante la observación de las imágenes y el diálogo que cada uno establecía con su personaje.

Para que el taller de mediación artística funcione es necesario crear un espacio en el que los participantes puedan expresarse sin miedo a ser juzgados, ridiculizados o censurados. En el segundo taller, la combinación del video y la performance se consideró interesante por generar un «espacio transicional», que permite la transferencia de relatos que no tenían otro lugar donde expresarse (Winnicott, 1997). En este espacio ambiguo entre real y ficticio (soy yo/no soy yo), se puede manifestar aquello que incomoda a la persona sobre lo que ha construido como su identidad sin sentirse juzgada, ya que se trata de una ficción.

Por otro lado, y en línea con los objetivos generales del Centro de Día, los talleres fomentaban la autonomía personal y el aprendizaje de habilidades sociales. Se perseguía una implicación progresiva de los usuarios en la decisión de los contenidos y la dirección de la actividad. La planificación de las grabaciones favorecía la adquisición de hábitos y organización.

En las actividades, el rol del educador artístico se plantea como acompañamiento al proceso de creación, aportando conocimientos técnicos cuando es necesario.

\subsection{Desarrollo del proyecto}

\subsubsection{De la caricatura al video}

En una primera fase se planteó un taller de caricaturas. La identidad se trataba desde la re- 
presentación humorística del rostro. Para ello, se explicaban nociones básicas sobre proporción, expresión y utilización de técnicas como dibujo, pintura o collage. La aplicación de un enfoque de tipo académico, resultó ser rígida y desaprovechaba el potencial del trabajo en grupo. Tras varias sesiones, se decidió adoptar el modelo de mediación artística (Moreno, 2010), potenciando la horizontalidad en la toma de decisiones y el trabajo grupal, a fin de integrar la diversidad de intereses de los participantes y trabajar aspectos como la colaboración y la negociación. En esta fase, el grupo decidió que quería llevar a cabo una representación de títeres.

Sin embargo, el trabajo manual de preparación limitaba el tiempo para construir las historias, la interpretación, con lo que los intereses de ciertos participantes no quedaban cubiertos. Como solución, se optó por hacer las representaciones con objetos encontrados, que podíamos transformar según el caso.

Tomando como referencia los trabajos con colectivos en riesgo de exclusión de Raúl Ayala y Pierre Bongiovanni (2006). Se propuso emplear una cámara de video para registrar las representaciones. Esto permitía el trabajo desde un plano artístico con una técnica sencilla en el uso y familiar. Por otro lado, permitía la introducción de la experimentación y la didáctica sobre el lenguaje televisivo y cinematográfico.

De cara a las representaciones, la diversidad y especificidad de roles (escenógrafo, guionista o decorador, cámara o efectos sonoros) permitía una mejor vinculación a los intereses personales de los participantes. La estructura del taller quedó distribuida en cuatro partes. Primero, se dedicaron varias sesiones a la creación del argumento. Por su valor didáctico y carácter colectivo, se optó por emplear la técnica del «cadáver exquisito» en esa parte del proceso. En una segunda fase se llevó a cabo la representación de la historia y su registro. Tras cada sesión dedicada a la grabación se llevaba a cabo el visionado y selección de las imágenes. Dado que las instalaciones no contaban con el equipo necesario, la edición era llevada a cabo por el educador artístico, que llevaba el material editado al taller semanal- mente. Esto permitía el visionado crítico y análisis de las grabaciones, aprovechando para introducir algún nuevo recurso técnico o mostrar algún referente cinematográfico o televisivo relacionado.

Destacamos dos sesiones dedicadas a la construcción de secuencias utilizando el «stopmotion ${ }^{2}$. Ocasionalmente se trasladó la actividad del taller al exterior. La espontaneidad del proceso de creación y los giros argumentales de las tramas dieron lugar a sesiones de grabación y fotografía sobre temas como «el color rojo» o «la naturaleza» (Criado, 2010). Esto sirvió de excusa para plantear descubiertas del barrio, incluso otras zonas de la ciudad. Finalmente se grabaron dos historias.

\subsubsection{Taller de video-performance}

Este taller se dividió en dos fases, aunque en la práctica la separación entre ellas no fuera estricta. La primera la denominamos «Reflexiones y experiencias en torno a la identidad que hemos construido», y fundamentalmente trataba de cuestionar la noción de identidad, especialmente a través del medio fotográfico, realizando autorretratos en los que cada participante recreaba una o varias identidades, con la ayuda de los demás. Para ello, previamente se realizan una serie de actividades que invitan a reflexionar en torno a dicha noción de identidad, se analiza la obra de artistas que han trabajado con ella de forma subversiva, y se estudian las posibilidades que ofrece el retrato y el medio fotográfico. El desarrollo de esta primera etapa promovía un clima de distensión en el que nadie se sintiera juzgado por su trabajo. Promovía la sensación de capacidad para utilizar una identidad distinta a conveniencia y emplear los lenguajes artísticos consecuentemente.

La segunda parte, que denominamos «Creación colectiva de un audiovisual», consistía en la realización de un trabajo audiovisual a partir de las distintas conclusiones que el grupo había extraído de la fase anterior. A continuación, se pretendía ver de qué manera se relacionaba cada uno de los participantes con la historia recreada en el vídeo, para finalmente invitarles a narrar visualmente una historia personal, a partir de dicha reflexión. Se trataba de un trabajo aún más abierto y modificado según las necesida-

\footnotetext{
${ }^{2}$ Consiste en crear una animación a partir de una serie de fotografías.
} 
des del grupo, aunque incidiendo en el cuestionamiento y desmantelamiento de las identidades fijas o estables. Dado que cada participante creaba de manera autónoma el personaje a representar en el vídeo, esta fase facilitaba que los usuarios se proyectasen de manera inconsciente en la historia, ayudándoles esta circunstancia a superar sus conflictos. Además, las tomas se realizan a partir de la improvisación de situaciones. Dichas situaciones se acordaban entre los que intervenían en ese momento en escena, y una vez pactada la acción se improvisaba ante la cámara de vídeo en la mayoría de casos con una única toma, y en otros casos en dos o tres secuencias.

Esta segunda etapa, en la que es fundamental la improvisación, y el usuario se ve obligado a participar activamente en la toma de decisiones, permite a cada uno trabajar desde sí mismo y fomenta la capacidad de proyectar nuevas consideraciones sobre su persona.

\subsection{Presentación de los talleres en la Uni- versidad}

Al finalizar cada uno de los módulos, algunos de los usuarios acompañados por la educadora social del centro y los educadores artísticos participaron en clases de la Facultad de Bellas Artes, presentando ante los estudiantes el proyecto y sus experiencias. Concretamente, durante el curso 2010-2011, en la asignatura Intervención Educativa en el Contexto Social, se presentó la experiencia del taller de la caricatura al vídeo, con la participación de los usuarios que habían participado, y del mismo modo, al final del mismo curso se cerraba la asignatura Proyectos de Educación Artística, con la participación de los usuarios que habían participado en el Taller de vídeo-performance.

Este tipo de colaboración, no sólo resulta enriquecedora por la oportunidad que supone para unos y otros tener un intercambio de este tipo, sino que además se propician nuevas relaciones de colaboración. Algunos de los estudiantes que estuvieron presentes se animaron a participar como voluntarios en proyectos puntuales.

\section{La voz de los participantes}

Con el objetivo de recoger la valoración de los participantes en las actividades de mediación artística realizadas en el centro, les propusimos hacer un grupo de discusión. Estuvieron presentes 14 usuarios del Centro de atención y seguimiento a las Drogodependencias, la educadora social del centro y la docente, además de una persona que grabó la sesión en vídeo. $\mathrm{Al}$ inicio de la sesión se planteó al grupo que realizamos estas actividades de mediación artística porque creemos en la capacidad transformadora de las artes y que este tipo de actividades son una herramienta en el trabajo para la reinserción social, y que el objetivo del encuentro es discutir con ellos sobre este tema y conocer su opinión como participantes en las actividades. El grupo de discusión tuvo una duración de una hora y media. Todos los participantes aportaron su opinión en torno a los temas planteados.

A continuación presentamos unos fragmentos de sus aportaciones que nos parecen significativos:

A mí me ha ayudado muchísimo; me ha dado mucho placer, me ha hecho reír cuando estaba muy deprimida, me ha hecho reconocerme a mí misma sin temor, y por tanto hay un antes y un después. Me ha proporcionado mucho bienestar, placer, comunicación con los compañeros; me he abierto mucho, y ha sido un empujón muy fuerte que no olvidaré nunca. Yo desde entonces no he parado, me he continuado abriendo, porque estaba muy cerrada. Ahora estoy haciendo teatro. Me ha servido de muleta para darle normalidad a mi vida, para mejorar incluso en relación a antes de estar enferma. Fantástico. Ha sido un catalizador. Esta transformación la he hecho sin esfuerzo. Me ha salido rodado. Me han dirigido de una manera para que saliera todo de mí sin que yo me sintiera forzada por ningún lado, de una forma totalmente placentera. Nosotros hemos pasado por la experiencia de las drogas que es como un viaje iniciático. El arte también es transformador. Es un viaje iniciático que te transforma. Te hace evolucionar, te hace aprender, abrirte en todos los sentidos. Te da mucho placer; como una droga. Seria paralela una experiencia a la otra. Las drogas las tomamos porque nos dan satisfacción. El arte nos sirve porque nos da mucho placer.

Yo cuando entré tenía la autoestima por los suelos. Tenía vergüenza por todo y aquí subí. La autoestima me subió hasta arriba. Me sentí especial porque nunca había hecho nada así, y el compartirlo con todos, y que siempre contaran conmigo, me hizo sentirme especial. 
Yo nunca había hecho esto, y muy bien. A parte te acostumbras a hacer cosas en grupo. Eso es importante para nosotros, ya que siempre hacemos las cosas a nuestra manera sin contar con nadie.

Algunos participantes también destacaron la importancia que tuvo para ellos la experiencia de ir a la Universidad:

Fui a la Universidad y nos recibieron estupendamente. Estuvo fantástico. Estuvimos como en casa. Nos recibieron con los brazos abiertos. Fue una gran experiencia porque nunca había estado. No tenía nada que ver con las películas americanas. Estuve encantado.

Estuvo bien porque yo personalmente tengo la percepción de haberme drogado, de ser un bicho raro que no encajo en ningún lado. Llegar a la Universidad, encontrar unas personitas que te escuchan, que les importa tu testimonio, que valoran el esfuerzo que estás haciendo, y que ellos se enriquezcan con tus comentarios, te hace sentir muy bien. Piensas: puedo ser útil y no soy un bicho raro. Simplemente he pasado por un mal momento en mi vida, pero eso no quita que haya gente que me reconozca el mérito de salir de las drogas, de ser aceptado socialmente otra vez, que no voy a ser un bicho raro toda mi vida. Y estar ahí y ver que te escuchan en candeletas fue una experiencia muy positiva.

\section{Conclusiones}

Desde el Centro de Atención y Seguimiento a las Drogodependencias se observa que los pacientes que acuden al Centro de Día mantienen en el tiempo una mayor abstinencia, aumento de la capacidad de concentración, memoria y bienestar tanto físico como mental, favorece la adherencia al tratamiento y la relación con los profesionales. El trabajo en grupo permite establecer relaciones de confianza, compromiso y autoestima, mejorando la relación familiar y con el entorno. Las actividades del Centro de Día, estimulan y son necesarias como mejora para la vida diaria. Por su parte, el enfoque de trabajo desde la mediación artística se evidencia como óptimo para trabajar con personas con problemas de adicciones puesto que fomenta sus habilidades sociales y la circulación social de cara a su reinserción. Esto sumado al trabajo con el concepto de identidad de los talleres, ayudó a cuestionar la imagen estereotipada del toxicómano.
Analizando el contenido de las aportaciones del grupo de discusión aparecen ideas como: placer, bienestar, comunicación con los compañeros, desinhibición, darle normalidad a la vida, la capacidad transformadora del arte, sacar lo mejor de cada uno, hacer cosas fuera de lo cotidiano y que inicialmente pensaban que no serían capaces, elevación de la autoestima, la importancia de trabajar en grupo en contra del individualismo habitual en sus vidas, creer en las capacidades propias, conocerse un poco más, desarrollar la constancia y la responsabilidad. Estas reflexiones del grupo en relación a qué les ha supuesto participar en el proyecto, evidencia que se han asumido los objetivos planteados y que las actividades de fotografía y vídeo, desde la metodología mediación artística son una herramienta válida para trabajar con personas con problemas de adicciones.

A nivel práctico, se observó que el uso de técnicas pictóricas era problemático para algunos participantes, que se sentían incómodos por considerar «no saber dibujar o pintar». La introducción de técnicas audiovisuales permitió revertir la situación, eliminando esta barrera técnica. La fotografía y el vídeo han sido actividades que han generado muy buena disposición en los participantes. En el primer taller, permitió reorientar el proceso a aspectos como la construcción del argumento, la interpretación, o el manejo de la cámara, aumentando la actividad e interacción entre los miembros del taller.

A lo largo del proyecto, el proceso fue ganando en complejidad: los usuarios prestaban más atención a la construcción de las imágenes, ya fuera para ilustrar el argumento o representarse a sí mismos. Descubrieron e incorporaron progresivamente nuevos recursos necesarios para la materialización de sus ideas y que daban pié a explicaciones técnicas o visionados del trabajo de artistas que se relacionaban con su trabajo. Esto, permitió también tratar cuestiones de educación visual. Por ejemplo, en una de las salidas, tres personas grabaron imágenes sobre el tema «La naturaleza es una de las cosas más hermosas de la vida». El visionado posterior, permitía comparar las tres visiones, las formas y contraponerlas a la propia.

El uso de un enfoque de mediación artística en el planteamiento de la estructura de las sesiones y en el rol del educador artístico, que se relacionaba de forma horizontal con los parti- 
cipantes y que trabajaba de forma colaborativa con ellos, permitía desligar el taller de la dinámica habitual de otras actividades del centro. La estructura flexible que se adopta fue capaz de acomodar los cambios que surgían sobre la marcha e integrar la diversidad de intereses de los participantes, lo que se tradujo en mayor interés y participación. A nivel de la reinserción y la adquisición de habilidades, valoramos positivamente las salidas efectuadas fuera del recinto del centro en el marco de los talleres. Destacamos las salidas puntuales para registrar imágenes, que favorecían la interacción entre los participantes, el medio y los vecinos.
Destacamos también las visitas a la Facultad de Bellas Artes, enriquecedoras por ser una oportunidad para el intercambio y propiciar nuevas relaciones de colaboración.

Por último, el haber recogido la opinión de los participantes a partir del grupo de discusión y que sepan que estamos escribiendo sobre la experiencia significa para ellos y para nosotros una forma de dar continuidad del trabajo realizado, de reconocer el esfuerzo de todos y reforzar la autoestima del grupo. Consideramos que la participación en este proceso ha promovido su empoderamiento y su proyección hacia el futuro de una forma más integrada.

\section{Referencias bibliográficas}

Aparicio Acosta, Felipe M. (2000). Universidad y sociedad en los albores del 2000. Relieve, 6 (1). Disponible en http://www.uv.es/RELIEVE/v6n2/RELIEVEv6n2_3.htm (Consultado 21/6/2011)

Ayala, R. (15/09/2009). Maldita Ley (10 videos producidos clandestinamente en tres centros penitenciarios en la ciudad de Quito, 2004-2007). La Selecta. Revista Electrónica Disponible en: http://www.laselecta.org/2009/09/maldita-ley-raul-ayala/ (Consultado el 10/1/2012)

Berger, P. L., Ed. (1999), Los límites de la cohesión social. Conflictos y mediación en las sociedades pluralistas. Informe de la Fundación Bertelsmann al Club de Roma. Barcelona: Galaxia.

Bongiovanni, P. Du coté des Abondances. Recuperado de: http://www.sklunk.net/DU-COTEDES-ABONDANCES-LE-FILM (Consultado el 10/1/2011)

Crespo, J y O'Ferral, C. (2005). Entrevista a José Crespo y Cristina O'Ferral, especialistas en asistencia y prevención de las drogodependencias. Disponible en: http://www2.uca.es/revista/uca-investiga/marzo-abril/adicciones.htm (Consultado el 1/2/2011)

Criado, C. (2011). Natural. Recuperado de: http://carloscriado.blogspot.com/2011/01/natural.html (Consultado el 1/2/2011)

Freire, P. (2005). Pedagogía del oprimido. México: Siglo XXI

Jiménez Vivas, A. (2009). Reflexiones sobre la necesidad de acercamiento entre universidad y mercado laboral. Revista Iberoamericana de Educación 50 (1). Disponible en: http://www.rieoei.org/deloslectores/2895Vivas.pdf (Consultado el 1/2/2011)

Maffesoli, M. (2004). El tiempo de las tribus: el ocaso del individuo en las sociedades posmodernas. México, D.F.: Siglo XXI.

Moreno González, A. (25/03/2010). La mediación artística: un modelo de educación artística para la intervención social a través del arte. Revista Iberoamericana de Educación, 52 (2). Recuperado de: http://www.rieoei.org/expe/3422Moreno.pdf (Consultado el 1/2/2011)

Taylor, D. (2007). Hacia una definición de performance. Recuperado de: www.nyu.edu/tisch/performance (Consultado el 21/5/2010)

Winnicott D.W. (1997). Realidad y Juego. Barcelona: Gedisa. 